\title{
A win for the patient: Direct patient notification improves treatment rates of active Helicobacter pylori infection
}

\author{
Sriharan Selvaratnam ${ }^{1}$, Joey Yeoh ${ }^{1}$, John Hsiang ${ }^{2}$, Alasdair B Patrick²
}

1. Department of Internal Medicine, Middlemore Hospital, South Auckland, NewZealand

2. Department of Gastroenterology, Middlemore Hospital, South Auckland, NewZealand

\section{CLINICAL AUDIT}

Please cite this paper as: Selvaratnam S, Yeoh J, Hsiang J, Patrick AB. A win for the patient: Direct patient notification significantly improves treatment rates of active Helicobacter pylori infection. AMJ 2014, 7, 8, 350-354. http://doi.org/10.21767/AMJ.2014.2132

\section{Corresponding Author:}

Dr Alasdair Patrick

Department of Gastroenterology,

Middlemore Hospital,

100 Hospital Road,

South Auckland, New Zealand.

Email: alasdair.patrick@middlemore.co.nz

\section{ABSTRACT}

\section{Background}

Current international guidelines recommend the commencement of effective eradication therapy as soon as active Helicobacter pylori (H. pylori) infection is confirmed. At our institution, all positive Campylobacter-like Organism (CLO) test results were automatically communicated to general practitioners (GPs) via a standardised letter, which also advised the commencement of eradication therapy. Despite this endeavour, a clinical audit conducted in 2011 demonstrated that only 66 per cent of confirmed H. pyloripositive South Auckland patients received eradication treatment and only 83 per cent of these patients received treatment within one month.

\section{Aims}

Improve the timely initiation of $H$. pylori eradication therapy through direct patient notification.

\section{Method}

A prospective clinical audit of 109 consecutive outpatients with a positive CLO test identified at gastroscopy. In addition to standard general practitioner notification, patients were also directly notified of their positive CLO test result via a standardised letter, which provided information about $H$. pylori and its disease associations as well as advising patients to seek consultation with their GP to commence eradication therapy. Dispensing data was examined using Test Safe electronic records to determine the total uptake and timing of treatment compared to data from a preliminary 2011 audit.

\section{Results}

Ninety-five per cent of $H$. pylori-positive patients received standard triple therapy; therefore, treatment of active $H$. pylori infection was significantly higher when patients were directly notified in addition to standard GP notification, when compared to GP notification alone (95 per cent vs 66 per cent, $p<0.001)$. All patients who received eradication therapy did so within one month of notification, a significant improvement compared to data from the previous audit in 2011 (100 per cent vs. 83 per cent, $p<0.001)$.

\section{Conclusion}

Direct patient notification using a standardised letter is a simple and economical strategy that significantly improves the timely initiation of eradication therapy for active $H$. pylori infection. This has since been integrated into standard practice at our District Health Board (DHB).

\section{Key Words}

Helicobacter pylori, H. pylori, patient education, triple therapy

\section{Implications for Practice:}

\section{What is known about this subject?}

Treatment initiation for active $H$. pylori infection in South Auckland has been well below international guidelineswith up to one-third of $H$. pylori-positive patients receiving no treatment at all.

\section{What new information is offered in this case study?} Direct patient notification is a simple and economical strategy that has improved the timely treatment of active $H$. 
pylori infection in a representative South Auckland population.

3. What are the implications for research, policy, or practice?

Patient empowerment has an important positive effect on treatment uptake.

\section{Background}

Helicobacter pylori (H. pylori) is strongly implicated in the pathogenesis of chronic gastritis and peptic ulcer disease. ${ }^{1,2}$ It is also considered a Class I human carcinogen for gastric adenocarcinoma and mucosa-associated lymphoid tissue (MALT) lymphoma. ${ }^{3,4}$

Due to the significant potential for morbidity and healthcare costs associated with active $H$. pylori infection, it is widely recommended that confirmed $H$. pylori infection is treated as soon as possible. ${ }^{1,2}$ For the individual patient, the benefits of $H$. pylori treatment include proven promotion of ulcer healing, reduction in ulcer recurrence, and reduced incidence of malignancy. ${ }^{5,6}$ The most commonly used firstline eradication regimen is the ubiquitous triple therapy consisting of a proton pump inhibitor, amoxicillin (or metronidazole for penicillin-allergic patients), and clarithromycin for a total of 7-14 days. ${ }^{7}$

In New Zealand, rapid urease testing using the CLO test is the standard diagnostic modality used for the detection of active $H$. pylori infection during endoscopy. Instead of routinely following up with individual patients with active $H$. pylori infection in a tertiary setting, the standard practice at our District Health Board (DBH) involved automatic communication of all positive outpatient CLO test results to GPs in the form of a standardised letter that also advised the commencement of eradication therapy. Despite this, a prospective clinical audit (2011) of 150 CLO-positive outpatients at our DHB demonstrated that 34 per cent $(n=51)$ never received any eradication therapy and only 83 per cent $(n=82)$ of those who did, received it within one month of notification (a further 13 per cent received treatment after one month but within three months and 4 per cent were treated after three months).

Therefore, we sought to examine the impact of direct patient notification, in addition to standard GP notification on the timing and total treatment rates of active $H$. pylori infection in a population of South Auckland patients by conducting a prospective clinical audit building upon the data garnered from the preliminary audit completed in 2011 (with free access to the prior unpublished data).

\section{Method}

From January 2012 to August 2012 all patients undergoing outpatient gastroscopies at Counties Manukau District Health Board were prospectively screened. Patients with positive CLO tests confirmed by gastroscopy were included. Patients with severe cognitive impairment and gastrointestinal malignancy were excluded (in accordance with the previous audit).

In addition to standard GP notification, all patients with a positive CLO test were also directly notified of their positive result (Dual Notification group). This was achieved by sending out a letter that provided background information about $H$. pylori and its disease associations. It also educated patients about the importance of timely treatment and they were thus advised to arrange an appointment to see their GP for further advice and to commence eradication therapy. The 2011 audit patient subset involving standard GP notification (GP notification only) was used as the "historic" control group. The primary outcome examined was time to receiving $H$. pylori eradication treatment, and the secondary outcome examined was total treatment uptake.

Basic demographic data including patient age, gender, and ethnicity were collected using up-to-date Concerto electronic records. Electronic Test Safe dispensing records (a medical information sharing service provided by the northern region District Health Boards) were analysed to determine the initiation and timing of specific $H$. pylori treatment for comparison with the historic group. The difference in demographic characteristics between the two groups was examined using two sample t-tests for age and chi-square test for gender and ethnicity. Time to treatment was defined as the time from CLO test positivity notification to the time of eradication therapy commencement. Time to treatment analysis was performed using Kaplan Meier analysis and the Log-rank test was used to determine the significance of this time-related event. All tests were twotailed and the chosen significance level $(\alpha)$ was $<0.05$.

\section{Results}

Baseline patient demographic data was compared between the two data sets with no difference found for mean age, gender, or ethnicity (Table 1 ).

In the Dual Notification group, 104 out of 109 (95 per cent) CLO test-positive patients received eradication therapy compared to 66 per cent in 2011. All treated patients received triple therapy within one month of positive CLO test notification. Therefore, the treatment of active $\mathrm{H}$. pylori 
infection was significantly higher in the Dual Notification group: 95 per cent vs. 66 per cent, $p<0.001$.

Table 1: Patient demographics between the two groups

\begin{tabular}{|r|c|c|c|}
\hline & $\begin{array}{c}\text { GP } \\
\text { Notification } \\
\text { only } \\
\text { (2011) }\end{array}$ & $\begin{array}{c}\text { Dual } \\
\text { Notification } \\
\text { system } \\
\mathbf{( 2 0 1 2 )}\end{array}$ & p value \\
\hline Demographics: & & & \\
\hline $\begin{array}{r}\text { Mean Age } \pm \text { SD } \\
\text { (Years) }\end{array}$ & $55.2 \pm 17.4$ & $56.8 \pm 14.4$ & 0.43 \\
\hline Gender: (\%) & & $50(46)$ & 1.00 \\
\hline Male & $71(47)$ & $34(31)$ & 0.43 \\
Ethnicity: (\%) & $36(24)$ & $23(21)$ & \\
Esian & $41(27)$ & $24(22)$ & \\
Maori & $28(19)$ & $28(26)$ & \\
Pacific People & $45(30)$ & 109 & \\
\hline Total Patients & 150 & & \\
\hline
\end{tabular}

Of the patients who received eradication therapy, the rate of treatment initiation within one month was also significantly higher in the Dual Notification group (100 per cent vs. 83 per cent, log-rank, $p<0.001$ ) (Figure 1).

Figure 1: Time to receiving treatment

\section{Time to Treatment}

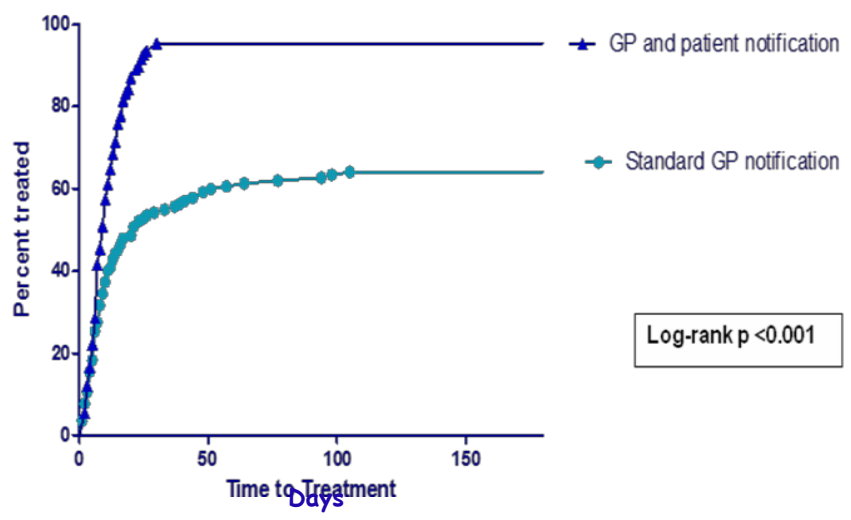

Time to receiving treatment (Days): curve of standard GP notification vs. GP/patient dual notification system

\section{Discussion}

The prior 2011 audit provided the impetus to examine an alternative method of improving total and timely treatment initiation for the eradication of confirmed $H$. pylori infection. Previous GP notification alone produced relatively poor treatment initiation rates with one-third of patients receiving no treatment at all.
Although not specifically audited previously, possible explanations for the poor performance in treatment initiation could include:

1. There were incorrect primary GP contact details on hospital records or patients were changing GP practices.

2. GPs did not receive notification letters.

3. GP practices were unable to contact patients.

4. Patients did not understand the importance of commencing and completing treatment.

Several studies have demonstrated increased levels of treatment initiation and adherence when patients were given more information about their illness. ${ }^{8-11}$ The positive effects of patient education on treatment uptake have been described previously in the literature; however, there is a paucity of data from Australasia, especially pertaining to $H$. pylori eradication therapy.

A randomised study conducted in Ireland demonstrated a statistically significant improvement in treatment initiation and compliance (92.1 per cent vs. 23.7 per cent, $p<0.001$ ) as well as overall eradication rate $(94.7$ per cent vs. 73.7 per cent, $p<0.02$ ) in patients who were randomised to receive education from a hospital pharmacist. ${ }^{12}$ A similar randomised study conducted in the state of Massachusetts in the United States demonstrated a statistically significant difference in the number of patients taking more than 90 per cent of their prescribed triple therapy regimen when they received education upon initiation of treatment (89 per cent vs. 67 per cent, $p<0.01) .^{13}$

Given the pathogenicity of $H$. pylori, it was clear that a more effective system for the notification of positive CLO test results was required at our DHB to prevent progression of disease due to delayed treatment or non-treatment of active $H$. pylori infection. We felt that such a system required empowering the patient with important information regarding $H$. pylori so that they may make informed decisions to seek treatment, as well as informing GPs about their patient's diagnosis. In addition, this would prevent failure to initiate treatment, or to initiate treatment in a timely manner resulting from breakdown in communication between the hospital, the patient, and the patient's GP.

Direct patient notification and education by means of an automatically generated standardised letter has several significant advantages over other forms of patient education. First, CLO tests may take several hours to demonstrate a positive result (in those with low bacterial 
load), therefore, the result may not be known until well after the patient has gone home. Any attempt at empirically educating the patient about active $H$. pylori infection and its implications during recovery from sedation in an endoscopy suite is unlikely to permit a conversation of sufficient depth to motivate and empower the patient to commence treatment if it is required. Second, by advising patients to arrange an appointment with their GP to obtain eradication therapy, it is likely that patients would have further opportunity to ask questions about their treatment and obtain further education about their diagnosis. Finally, the use of a standard template for letter preparation also ensures that this method of communication is easily reproducible and economical.

The outcomes of this study have since resulted in a change in standard practice within our $\mathrm{DHB}$ - with all positive CLO test results currently being communicated directly to patients as well as their GPs using easily reproducible letters, which are similar in content to what was used in this study.

Despite the significant improvement in timely treatment initiation achieved with direct patient notification in addition to GP notification, there are limitations to be considered. First, in addition to timely treatment initiation, successful eradication also requires satisfactory patient compliance as well as a favourable antibiotic resistance profile. Second, the South Auckland population is a multicultural society with a relatively higher proportion of non-English speaking individuals. ${ }^{14}$ In this study, patient notification letters were only printed in the English language. Therefore, in conjunction with English, the use of appropriately translated language-specific letters are likely to overcome potential language barriers in non-English speaking households.

\section{Conclusion}

Direct patient notification is a simple and economical strategy that has significantly improved the timely treatment of active $H$. pylori infection in a population of South Auckland patients. The findings of this clinical audit support the evidence from previous studies, which demonstrated significantly increased levels of treatment initiation and adherence in patients who had been given more information about their illness. The previously poor treatment rates of active $H$. pylori infection in South Auckland have thus been identified, successfully addressed and re-audited, hence closing the current audit cycle.

\section{References}

1. Chey WD, Wong BC. American College of Gastroenterology guideline on the management of Helicobacter pylori infection. Am J Gastroenterol. 2007;102:1808-25.

2. Hung IF, Wong BC. Assessing the Risks and Benefits of Treating Helicobacter Pylori Infection. Therap Adv Gastroenterol. 2009;2(3):141-7.

3. Dixon ME. Pathology of gastritis and peptic ulceration. In: Mobley HLT, Mendz GL, Hazell SL, eds. Helicobacter pylori: physiology and genetics. Washington D.C:ASM Press 2001:459-69.

4. Huang JQ, Sridhar S, Chen Y, Hunt RH. Meta-analysis of the relationship between Helicobacter pylori seropositivity and gastric cancer. Gastroenterology. 1998;114(6):1169-79.

5. Leodolter A, Kulig $M$, Brasch $H$, Meyer-Sabellek W, Willich SN, Malfertheiner P. A meta-analysis comparing eradication, healing and relapse rates in patients with Helicobacter pylori-associated gastric or duodenal ulcer. Aliment Pharmacol Ther. 2001;15:1947-58.

6. Ford AC, Delaney BC, Forman D, Moayyedi P. Eradication therapy in Helicobacter pylori positive peptic ulcer disease: Systematic review and economic analysis. Am J Gastroenterol. 2004;99:1833-55.

7. Fock KM1, Katelaris $P$, Sugano $K$, Ang TL, Hunt R, Talley NJ, Lam SK, Xiao SD, Tan HJ, Wu CY, Jung HC, Hoang BH, Kachintorn U, Goh KL, Chiba T, Rani AA; Second AsiaPacific Conference. Second Asia-Pacific Consensus Guidelines for Helicobacter pylori infection. J Gastroenterol Hepatol. 2009;24(10):1587-600.

8. Gold DT, McClung B. Approaches to patient education: Emphasizing the long-term value of compliance and persistence. Am J Med. 2006;119(4):32-7.

9. Singal $A G$, Volk ML, Rakoski MO, Fu S, Su GL, McCurdy $\mathrm{H}$, Marrero JA. Patient involvement in healthcare is associated with higher rates of surveillance for hepatocellular carcinoma. J Clin Gastroenterol. 2011;45:727-32.

10. Emkey RD, Ettinger M. Considerations for improving compliance and persistence with bisphosphonate therapy for osteoporosis. Am J Med 2006;119:185-24S.

11. Hill J, Bird H, Johnson S. Effect of patient education on adherence to drug treatment for rheumatoid arthritis: a randomised controlled trial. Ann Rheum Dis. 2001;60:869-75.

12. Al-Eidan, McElnay JC, Scott MG, McConnell JB. Management of Helicobacter pylori eradication-the influence of structured counselling and follow-up. $\mathrm{Br} \mathrm{J}$ Clin Pharmacol. 2002;53:163-71. 
13. Lee M, Kemp JA, Canning A, Eqan C, Tataronis G, Farraye FA. A randomized controlled trial of an enhanced patients compliance program for Helicobacter pylori therapy. Arch Intern Med. 1999;159:2312-6.

14. Statistics New Zealand. 2013 census regional summary tables-part 1 [Internet]. Statistics New Zealand; 2013 (cited 2014 Mar 12]. Available From: http://www.stats.govt.nz/Census/2013-census/datatables/regional-summary-tables-part-1.aspx

\section{ACKNOWLEDGEMENTS}

The authors thank all participating General Practitioners as well as the endoscopy staff (medical, nursing and administrative) of the Gastroenterology Department, Middlemore Hospital.

\section{PEER REVIEW}

Not commissioned. Externally peer reviewed.

\section{CONFLICTS OF INTEREST}

The authors declare that they have no competing interests.

\section{ETHICS COMMITTEE APPROVAL}

Ethics committee review was not required for this clinical audit as stated in the standards set by The National Ethics Advisory Committee, The Ministry of Health, New Zealand. 